\begin{abstract}
S
Anne Faber

Further Development of the European Union: Deepening versus Widening?

This article investigates the strategies currently available to the European Union in the tension between deepening and widening. The goal of the article is to demonstrate that, out of the limited number of politically realistic strategies, none is currently able to meet the challenges posed to the new EU-27. Thus, instead of relying on traditional approaches to the question of deepening and widening, the European Union needs to find new, explicitly differentiated concepts and creative responses that can also easily be communicated to the citizens of the Union. The article concludes with a presentation of guiding principles for this kind of new deepening and widening strategy for the EU-27.
\end{abstract}

Kai-Olaf Lang and Daniela Schwarzer

Arguments for a New Enlargement Strategy - The Discussion on the Absorption Capacity of the EU

This article takes on the current debate over the integration capacity of the EU and investigates whether the new enlargement strategy, passed in December 2006, can effectively prevent vetoplayers (countries that hold a referendum or the European Parliament) from blocking an accession after the conclusion of negotiations. The authors do not view the resolutions so far as a sufficient answer and argue that the EU should strive for a sequencing of deepening and widening measures. Further enlargements should be accompanied by transparent criteria on the absorption capacity of the EU and by greater participation of national parliaments. There should be no attempt to define an absolute absorption capacity of the EU, rather should this be defined and politically communicated with regard to the specific candidate countries.

\title{
Peter-Christian Müller-Graff
}

\section{,Differentiated Integration': A Concept with Destructive or Unifying Force for the European Union?}

Differentiated integration within the EC/EU context refers to all concepts and forms of specific cooperation among a subset of EC/EU member states, which transcend the common acquis. To determine whether this kind of approach will have a destructive or rather a unifying effect for the $\mathrm{EC} / \mathrm{EU}$, one must draw certain distinctions, especially according to the timeframe (short-, medium- and long-term), the relation of a differentiation measure to the concept of the single market and its flanking policies - e.g. social policy, area of freedom, security and justice - (either obligatory, plausible or unrelated to the single market), the organisational location of the differentiation (inside or outside the EC/EU) and the configuration of member states. Against the backdrop of previous experience, it is clear that intelligent management of the means of differentiated integration can work in favour of a homogenous base for integration and bring about improvements that further unify the EC/EU.

Stephan Hobe and Andrea End

\section{Years of the Treaties of Rome - Precursors to a Modern Development of Law}

The signing of the Treaties of Rome on 25 March 1957 on the founding of EURATOM and the European Economic Community provides an occasion to place the history of integration under scrutiny. At the center of this examination are the processes initiated by the Treaties of Rome. 
From a legal perspective these processes can be demonstrated, especially by the terms of integration and supranationality, by the development of constitutional structures and finally by means of the term „confederacy of states“ (,Staatenverbund“). While the EURATOM Treaty adopted the sectoral supranational integration model of the European Coal and Steel Community in the field of nuclear industry for the preservation of peace in Europe, the EEC Treaty has created the legal framework for cross-sector governance at the European level. As a consequence of the Treaties of Rome, the EU has become the precursor to a modern development of law enhanced by the reciprocity and complementarity of the national and European legal framework.

\section{Waldemar Hummer}

\section{The European Institute of Technology and the European Research Council: Two In- struments of European Excellence}

To close the innovation gap between the EU on the one hand and the USA, Japan and the upand-comers', China and India, on the other, the European Council, in its so-called Lisbon Strategy of March 2000, set out to make the EU the „most competitive and dynamic knowledgebased economy in the world“ by 2010. In order to reach this ambitious goal, investment in research and technological development would have to see a massive increase. Accordingly, the 7th Research Framework Programme of the EC (2007-2013), as a part of the programme ,Ideas", envisioned the creation of a ,European Research Council', which was officially established at the beginning of February 2007. In November 2006, the Commission additionally proposed a regulation that would establish a ,European Institute of Technology '.

\section{Xavier Pacreau and Andreas Schwab}

\section{Thoughts on the Liberalisation of the European Defence Equipment Market}

The European defence equipment market today is in many critical areas still fragmented into individual national markets. The varied application of Article 296 of the EC Treaty, which defines the possibilities for an exception for member states in ,essential security interests', prevents the formation of a common European market. In March 2003, the European Commission announced several initiatives, with which it sought to create a European defence equipment market and thus make more efficient the development, production and procurement of defence equipment in Europe. This article discusses and evaluates the proposals of the European Commission, with particular regard for the interpretation of Article 296 of the EC Treaty.

Jorgo Chatzimarkakis and Lutz Dommel

\section{Shaping European Policy Efficiently - The Example of the Competitiveness and Inno- vation Framework Programme}

In early 2007, the Competitiveness and Innovation Framework Programme (CIP) of the European Union was launched, with a total volume of expenditure of around 3.6 billion euros. This article traces the path from the initial proposal of the European Commission to the final passage of the legislation. The analysis shows the perspective of the responsible rapporteur in the European Parliament and brings into focus the diverse interactions of the European institutions. Throughout, the idea of a ,functioning Europe ' is portrayed and the influencing factors associated with a smooth legislative process are presented.

Übersetzung aus dem Deutschen von William L. Metzger. 